\title{
Radar data assimilation impact over nowcasting a mesoscale convective system in Catalonia using the WRF model
}

\author{
R. Cáceres ${ }^{1}$ and B. Codina ${ }^{1}$ \\ ${ }^{1}$ University of Barcelona, Barcelona, Spain
}

Received: 3-VII-2017 - Accepted: 10-XII-2017 - Original version

Correspondence to: rcaceres@meteo.ub.edu

\begin{abstract}
This study uses the Weather Research and Forecasting model (WRF) and the three-dimensional variational data assimilation system (WRF 3DVAR), in cold and warm starts, with the aim of finding out an appropriate nowcasting method that would have improved the forecast of precipitation maxima in the mesoscale convective system that occurred in Catalonia (NE Spain) on March 21, 2012 at 20 UTC. We assimilated radar data using different configurations, qualitatively verifying the increase of rainwater produced by the assimilation of reflectivity. While in cold starts the best result was obtained with a length scale of 0.75, in warm starts it was necessary to use a length scale of 0.25 . We got better results in all cases when radar data assimilation was used, and although one of the cold starts achieved the best result and correctly located precipitation maxima, the forecast amount was still lower than the observations.
\end{abstract}

Key words: WRF, 3DVAR, radar, precipitation

\section{Introduction}

Mesoscale Convective Systems (MCSs) are associated with heavy precipitation, strong wind gusts, floods, material damage and, eventually, loss of human lives. Therefore, identifying, analyzing and predicting these events has become one of the great challenges of the current weather numerical prediction systems.

The MCSs description and their influence in Spain has been extensively studied. Capel Molina (2000) indicates that these types of phenomena are accentuated due to the geographical location of the Iberian Peninsula, the direction of the flow coming from the Atlantic Ocean as a result of the seasonal variation in the general circulation of the atmosphere and the interaction of zones with high and low atmospheric pressure. Rigo and Llasat (2004) developed a methodology to classify the MCSs on the Mediterranean coast of the Iberian Peninsula based on radar data, the position of the convective and stratiform area, size, duration and amount of precipitation.

In addition, different techniques have been used in Spain in order to predict the precipitation caused by MCSs using the limited area model Weather Research and Forecasting (WRF) described in Skamarock et al. (2008). Mercader (2010) ran the WRF model with different microphysical combinations, Trapero et al. (2013) studied the influence of the Pyrenees mountain range on the precipitation processes using the WRF model with a high resolution in Catalonia and Arasa et al. (2016) employed the WRF model with assimilation of soundings and irradiance (from satellites) in the Port of Huelva. Nevertheless, we are not aware of previous studies carried out in Spain with radar data assimilation.

This research is focused on short term forecasts or nowcasting with time horizons of less than eight hours. One of the problems with nowcasting is the model spin-up time, because the short span between the forecast and the initial time does not allow the model to reach the appropriate balance between its variables. It is here that data assimilation plays an important role. Skamarock (2004), Jankov et al. (2007), Kain et al. (2010) and Yang et al. (2011) agree that a strong assimilation cycle minimizes the spin-up time, contributing to a better short range forecast.

This concept is introduced in the WRF model as the 
WRF Data Assimilation System (WRFDA), which can be used with three-dimensional variational (3DVAR) data assimilation according to Barker et al. (2004) or with four dimensional variational (4DVAR) data assimilation according to Huang et al. (2009); in either case, a new and updated initial state in the mesoscale model is produced based on the assimilated observations. An extensive description of WRFDA can be found in Barker et al. (2012).

The WRFDA can assimilate different types of observations: surface, sounding, wind profile, aircraft and irradiance data. Some of these data have the advantage of being available very close to the surface where the processes of heating and convection begin. But, apart from irradiance data, they have two major disadvantages as well: heterogeneous and poor spatial distribution (concentrated especially in urban areas) and few height data.

Unlike conventional data, radar data has high temporal, vertical and horizontal resolution, which allows a homogeneous spatial assimilation. Nevertheless it has the disadvantage of using indirect observations (reflectivity and radial velocity) measured with remote sensing techniques instead of model variables.

Radar data assimilation within weather forecast models, such as WRF, causes an important modification of the background data. Since it assimilates large amounts of data in all levels of the troposphere where the MCS is developed, this should theoretically have a positive effect on the forecast.

Although authors like Sun and Wang (2013) have shown the nowcasting results are more effective when using radar data assimilation with 4DVAR, this is not used due to its low operational application associated to the high computational costs.

In this study, radar reflectivity data is mainly assimilated using the indirect method proposed by Wang et al. (2013) and only one case uses the technique of Xiao et al. (2007). Radial velocity assimilation is made based on the methodology proposed by Xiao et al. (2005). A set of experiments are initialized using Global Forecast System (GFS) model outputs (cold starts) and others with previous WRF forecasts (warm starts) as a background.

The objective of this study is to find a nowcasting procedure to forecast the spatial distribution of precipitation and its maximum location and amount recorded on March 21, 2012 at 20 UTC in Catalonia, and to analyze the radar data assimilation impact over the precipitation caused by a MCS using the WRF model. The paper is organized in five sections: Section 2 summarizes the characteristics of the WRF - 3DVAR system, the radial velocity assimilation and the two methods of reflectivity assimilation available in version 3.9; Section 3 introduces the methodology, area and case of study, configuration of WRF, 3DVAR and data preprocessing; Section 4 presents the results and their discussion and Section 5 draws the final conclusions.

\section{WRFDA description}

\subsection{WRF 3DVAR system}

The WRF model includes the 3DVAR system, which combines forecasts of global or mesoscale models (first guess or background) with data of atmospheric variables (observations) in order to produce a new initial state (analysis) of the atmosphere closer to the real atmospheric conditions. This system has become an effective way to avoid the model spin-up problem, it gives more data assimilation control to the user and improves the background fields through the assimilation of different types of observations.

The 3DVAR system is based on the calculation of a cost function $J(x)$, considering the differences between the analysis and the background $\left(J^{b}\right)$ and between the analysis and observations $\left(J^{\circ}\right)$, formulated by Courtier et al. (1994):

$$
\begin{aligned}
J(x) & =J^{b}+J^{o} \\
& =\frac{1}{2}\left(x-x^{b}\right)^{T} \mathbf{B}^{-1}\left(x-x^{b}\right)+\frac{1}{2}\left(y-y^{o}\right)^{T} \mathbf{R}^{-1}\left(y-y^{o}\right)
\end{aligned}
$$

where:

$x$ : analysis of model variables at every grid point

$x^{b}$ : background or first guess

$y$ : model variables transformed by nonlinear observation operator $(H) . y=H(x)$

$y^{o}$ : observation

R: observation error covariance matrix

B: background error covariance matrix

The background error in the above-mentioned cost function is obtained by launching 24-hour forecasts every 12 hours for a period of one month. Then, the output of the 12 common hours of consecutive forecasts is compared. This is known as the National Meteorological Center (NMC) method, proposed by Parrish and Derber (1992) as a way to obtain statistical averages of control variables:

$$
\mathbf{B}=\overline{\left(x^{f 24}-x^{f 12}\right)\left(x^{f 24}-x^{f 12}\right)^{T}}
$$

where $x^{f 24}$ and $x^{f 12}$ are the 24 and 12-hour forecasts respectively, and the overbar represents an average over time and space.

In this point, the analysis increment $x^{\prime}=x-x^{b}$ proposed by Courtier et al. (1994) is used to minimize the cost function $J(x)$. This technique simplifies the background using the transformation operator $U$ and control variables $v$ under the restriction $\mathbf{B}=U U^{T}$, where $U$ represents the decomposition of $\mathbf{B}$ in its vertical $\left(U_{v}\right)$, horizontal $\left(U_{h}\right)$, and physical $\left(U_{p}\right)$ components. Thus, $x^{\prime}=U v$. The control variables $v$ can be selected by the user from four predetermined sets which are denoted in the WRFDA users' guide (NCAR, 2017) as CV3, CV5, CV6 and CV7.

The physical transform component converts the CV3 
control variables (stream function, velocity potential, unbalanced pressure and humidity) in terms of model variables, in this case wind components, pressure and relative humidity increments. The vertical transform component uses an empirical orthogonal function (EOF) decomposition of statistical covariance error. The horizontal transform component is a function of vertical transform that works with recursive filters in order to create a smoothing effect that is distributed in an isotropic and homogeneous way.

These filters use a correlation length scale parameter, which represents the radius of influence, calculated in grid point space, around the position of an observation. It is an input parameter for recursive filters to spread out the increment horizontally (Descombes et al., 2015). Since the temperature and relative humidity have more local characteristics, they are represented by a relatively small length scale. Therefore the analysis increment from these variables will be closer to the observation compared to the wind components (Descombes et al., 2015). WRFDA allows the user to artificially reduce or increase the magnitude of the length scales and variance of each control variable obtained with the NMC method. For example, a value of 0.75 would reduce the length scale parameter by $25 \%$ and 1.6 would increase the length scale by $60 \%$. The same applies to the variance.

After obtaining the background error covariances using statistical regression coefficients, the matrix is divided generating the background error correlation length scale for each variable and level. These control variables make it possible to reduce the model computing time and find the incremental analysis $x^{\prime}$.

Knowing that $y^{o^{\prime}}=y^{o}-H^{\prime}\left(x^{b}\right)$, where $H^{\prime}$ represents the linearization of nonlinear $(\mathrm{H})$, Equation 1 can finally be rewritten in terms of analysis increments, as shown in Barker et al. (2004).

\subsection{Radial velocity assimilation}

With the aim of using radar data as part of the assimilation system, Xiao et al. (2005) modified the WRF3DVAR in order to include vertical velocity increments by combining the continuity, hydrostatic and adiabatic thermodynamic equations in a single balanced equation. The observation operator for Doppler radial velocity (Equation 3) presents the relation between radial velocity $V_{r}$ and rainwater terminal velocity $v_{t}$ calculated according to Sun and Crook (1997):

$$
\begin{aligned}
& V_{r}=u \frac{x-x^{o}}{r}+v \frac{y-y^{o}}{r}+\left(w-v_{t}\right) \frac{z-z^{o}}{r} \\
& v_{t}=5.40\left(p_{s} / \bar{p}\right)^{0.4}\left(q_{r}\right)^{0.125}
\end{aligned}
$$

where:

$$
\begin{aligned}
& u, v, w: \quad \text { cartesian velocity fields }(\mathrm{m} / \mathrm{s}) \\
& x, y, z: \quad \text { radar position (always fixed) } \\
& x^{o}, y^{o}, z^{o}: \text { observation position }
\end{aligned}
$$

$\begin{array}{ll}r: & \text { distance between radar and observation } \\ p_{s}: & \text { surface pressure } \\ q_{r}: & \text { rainwater mixing ratio }(g / k g) \\ \bar{p}: & \text { base-state pressure }\end{array}$

\subsection{Reflectivity assimilation}

Since WRFDA version 3.7, there have been two available ways of assimilating reflectivity $(Z)$. The first way is the method proposed by Xiao et al. (2007). By using total water mixing ratio $q_{t}=\left(q_{v}+q_{c}+q_{r}\right)$ as a control variable and a warm rain parameterization (hydrometeor partition), it is possible to build a relationship between rainwater, $q_{r}$, cloud water, $q_{c}$, water vapor, $q_{v}$, and temperature. This leads to nonlinear Equation 4 proposed by Sun and Crook (1997):

$$
Z=43.1+17.5 \log \left(\rho q_{r}\right)
$$

In Equation 4, $Z$ represents the reflectivity (dBZ), $\rho$ the air density $\left(\mathrm{kg} / \mathrm{m}^{3}\right)$ and $q_{r}$ the rain water $(\mathrm{g} / \mathrm{kg})$. Equation 4 is transformed and used linearly according to the analysis incremental methodology generating the Equation 5:

$$
d Z=\frac{17.5 d q_{r}}{q_{r} \ln (10)}
$$

In this method, the first increment due to reflectivity assimilation occurs on rainwater and the above-mentioned relationship within warm rain processes causes increases in $q_{c}, q_{v}, T$ and even in the wind components $(u, v)$.

The second option for assimilating reflectivity is indirect, in which the rainwater mixing ratio and water vapor are assimilated and estimated from radar reflectivity using the rainwater mixing ratio as a control variable. This method was proposed by Wang et al. (2013) after finding large differences between the results presented by the operators of Equations 4 and 5. Moreover, it is not possible to apply Equation 5 when $q_{r}$ is not present and this is a great weakness in cold starts. In this new method, rainwater is calculated before the assimilation process, it has the advantage of not requiring a linear operator, hence Equation 4 can be used.

The case of water vapor is different. It still requires a linear observation operator. In 3DVAR 3.9, it is only possible to assimilate saturated water vapor if it fulfills two special characteristics: to have a reflectivity greater than a threshold (default $25 \mathrm{dBZ}$ ) and reflectivity above the base of the cloud with respect to the background. The observation is compared with the saturation water vapor background (calculated with pressure and temperature fields). Consequently, increases in relative humidity and temperature are obtained using the new linearized observation operator for $q_{v}$ as

$$
d q_{v} \approx q_{s} d R H+\frac{4302.6}{(T+243.5)^{2}} q_{v} d T
$$

where:

$q_{s}: \quad$ saturated specific humidity $(g / k g)$

$R H$ : relative humidity (\%) 


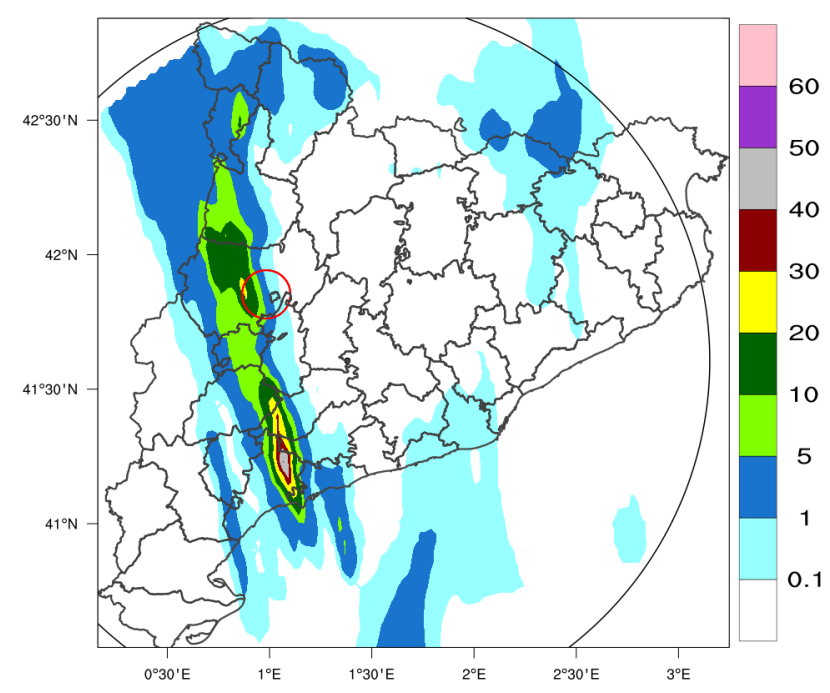

Figure 1: Observed precipitation from radar and rain gauge data (EHIMI product) from 19 to 20 UTC 21 March 2012. The red circle indicates the tornado location.

\section{$T: \quad$ temperature $(K)$}

Finally, the Wang et al. (2013) method can use cloud and vertical velocity control variables by adding radial velocity data $J^{V_{r}}$, rainwater data $J^{q_{r}}$ and water vapor data $J^{q_{v}}$ to the initial cost function (Equation 1) in this way

$$
J(x)=J^{b}+J^{o}+J^{V_{r}}+J^{q_{r}}+J^{q_{v}}
$$

\section{Methodology}

\subsection{Area and case study}

The study area was centered in Catalonia, located in the NE of the Iberian peninsula. The orography of Catalonia features two complex mountain systems, the Pyrenees and the Pre-Pyrenees to the North with elevations up to 3,143 m, and the coastal and pre-coastal ranges with elevations up to $1,706 \mathrm{~m}$ with a central depression between them.

Our case study is an event that took place in Catalonia on March 21, 2012, between 19 and 20 UTC. In this period, a Mesoscale Convective System (MCS) caused a precipitation maximum of $60 \mathrm{~mm}$ in Southern Catalonia (Fig. 1). Bech et al. (2015) described the synoptic situation that originated this MCS and classified it as a meso- $\beta$ elongated convective system (M $\beta$ ECS). This event produced precipitations greater than $100 \mathrm{~mm}$ in 24 hours and a tornado of category EF1 (Enhanced Fujita) with winds between 138 and $178 \mathrm{~km} / \mathrm{h}$.

\subsection{WRF configuration}

The WRF model version 3.9 was run in this study with Lambert Conformal conical projection, three one-way nested domains of 27, 9 and $3 \mathrm{~km}$ grid-point horizontal

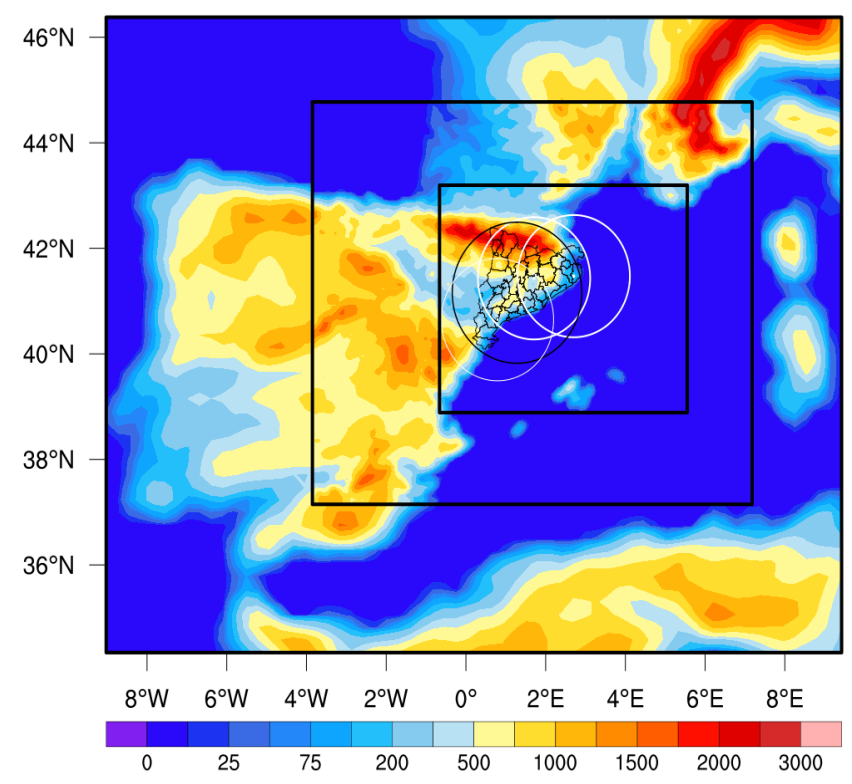

Figure 2: Study area with 3 nested WRF domains of 27, 9 and $3 \mathrm{~km}$ grid-point horizontal resolution and modeled topography $(\mathrm{m})$. Black circle represents the radar range for CDV $(148 \mathrm{~km})$ and white circles for the others $(128 \mathrm{~km})$.

resolutions with 51 full sigma levels in the vertical from surface to $50 \mathrm{hPa}$ at the top. The study area within the inner domain was completely covered by the radar network (Fig. 2) composed of four C-band radars: Puig Bernat (PBE), Creu del Vent (CDV), La Miranda (LMI) and Puig de Arques (PDA) operated by the Meteorological Service of Catalonia.

The physical sub-grid parameterizations used were Thompson microphysics scheme (Thompson et al., 2008), Rapid Radiative Transfer Model for shortwave and longwave radiation schemes (Iacono et al., 2008), Monin-Obukhov surface layer scheme (Monin and Obukhov, 1954), unified Noah land surface model (Mukul Tewari et al., 2004), lateral boundary conditions scheme with 4 relaxation points (Janjić, 1994), and Kain-Fritsch cumulus parameterization scheme (Kain, 2004) in domains 1 and 2, and convection-permitting approximation in domain 3 with no cumulus parameterization. The default geography and static data were generated with 30-second spatial resolution databases in every domain.

As initial and boundary conditions, we employed the 12 UTC GFS run, provided by the National Centers for Environmental Prediction (NCEP) at the highest resolution available before January $2015\left(0.5^{\circ} \times 0.5^{\circ}\right)$ with 47 isobaric vertical levels.

\subsection{Radar data preprocessing}

Before the assimilation process in 3DVAR, it was necessary to perform the following three steps:

First: Reflectivity and radial velocity extraction. The radar data had a time resolution of 6 minutes and was divided 


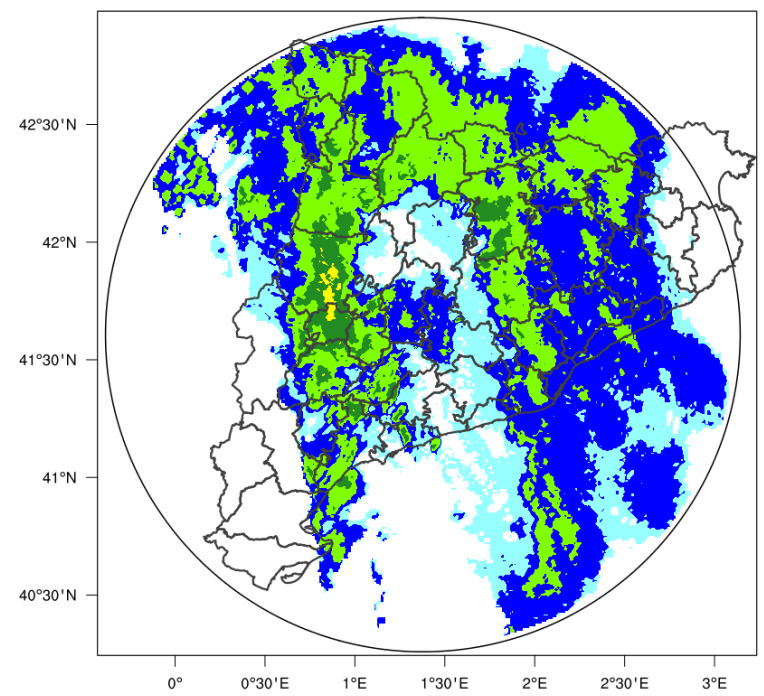

(a) Before (resolution $1 \mathrm{~km}$ )

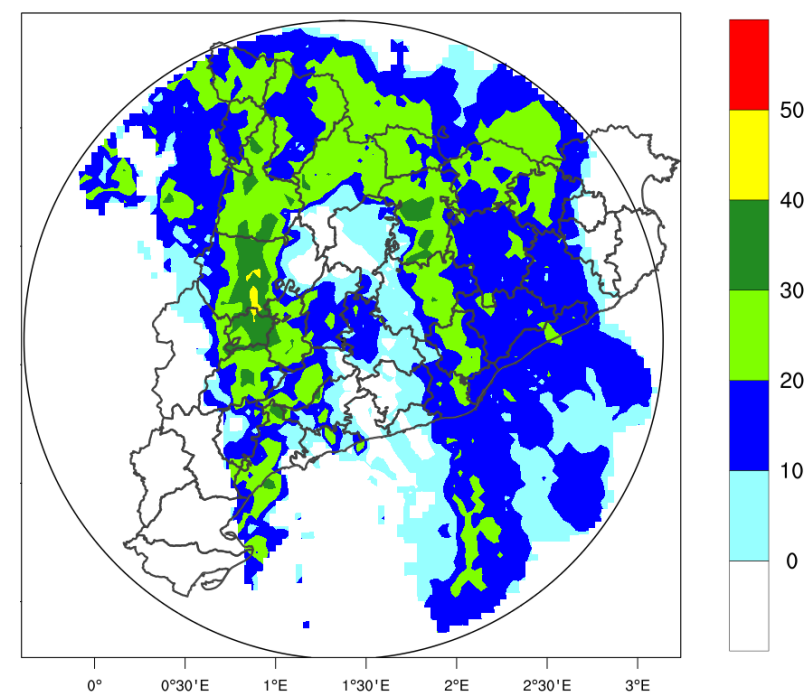

(b) After (resolution $3 \mathrm{~km}$ )

Figure 3: Maximum radar reflectivity (dBZ) before and after VDRAS-QC raw data processing at 15 UTC 21 March 2012.

into three volumes with increasing antena elevation angles. As only volumes 2 and 3 contained both radar reflectivity and Doppler radial velocity, volume 1 data was discarded and volumes 2 and 3 were used in the assimilation process with a maximum range of $148 \mathrm{~km}$ and $128 \mathrm{~km}$, respectively, according to the Table 1.

Second: Raw radar data were rewritten in Meteorological Data Volume (MDV) format using National Center for Atmospheric Research (NCAR) software. Applying an 8-point linear interpolation grid transformation, the radar spherical coordinates were changed to Cartesian coordinates over a $300-\mathrm{km}$ square with $1-\mathrm{km}$ grid-point resolution.

Third: The radar data used in the assimilation process were processed by the Quality Control Module (QC) of Variable Doppler Radar Assimilation System (VDRAS) developed by NCAR. VDRAS performs data filtering, eliminates velocity dealiasing, determines the vertical resolution of each grid point, assigns the observation specific error and downgrades the resolution of the radar to match that of the model, generating a $100-\mathrm{km}$ square with $3-\mathrm{km}$ grid-point resolution (Fig. 3). At the end of this process, 5,174 radial velocity and reflectivity data were obtained from the CDV radar, 3,205 from PDA, 3,122 from PBE and 2,164 from LMI radar.

\subsection{WRFDA configuration}

In most experiments, the WRFDA was set up with the radar data assimilation technique proposed by Wang et al. (2013) also allowing the assimilation of in-cloud humidity. Only one experiment was performed using the technique proposed by Xiao et al. (2007).

The number of outer loops was 1 , the background error chosen was CV7 because it improves the $0-12 \mathrm{~h}$ precipitation prediction (Sun et al., 2016). This set of control variables are the horizontal wind components, temperature, surface pressure, and pseudo relative humidity, defined by Dee and da Silva (2003).

The background error covariance matrix was generated according to the NMC method already mentioned but changing 24-hour forecasts every 12 hours for 12-hour forecast every 6 hours. Between September 24 and October 24,2016 , a total of 12012 -hour forecasts were generated at intervals of 6 hours $(00,06,12$ and 18 UTC). This period was chosen because, although the seasonal rainfall distribution in Catalonia is geographically diverse and contains 10 out of the 24 possible combinations, autumn is the rainiest season in most of the region. The background statistics for each domain were obtained using the WRFDA gen_be utility (NCAR, 2017). For every control variable, the background error covariance was set to 2.5 and length scales between 0.05 and 1.

The background from outer domains (domains 1 and 2) was not modified by 3DVAR. The outer domains keep the background from the real.exe initialization process. The lower and lateral boundary conditions for the inner domain $(3 \mathrm{~km})$ were updated after radar data assimilation according to the methodology proposed in the WRFDA Users' Guide for cold and warm starts.

\section{Results and discussion}

\subsection{Analysis}

Considering that an accurate analysis should improve the results of the forecast, it is necessary to configure the 


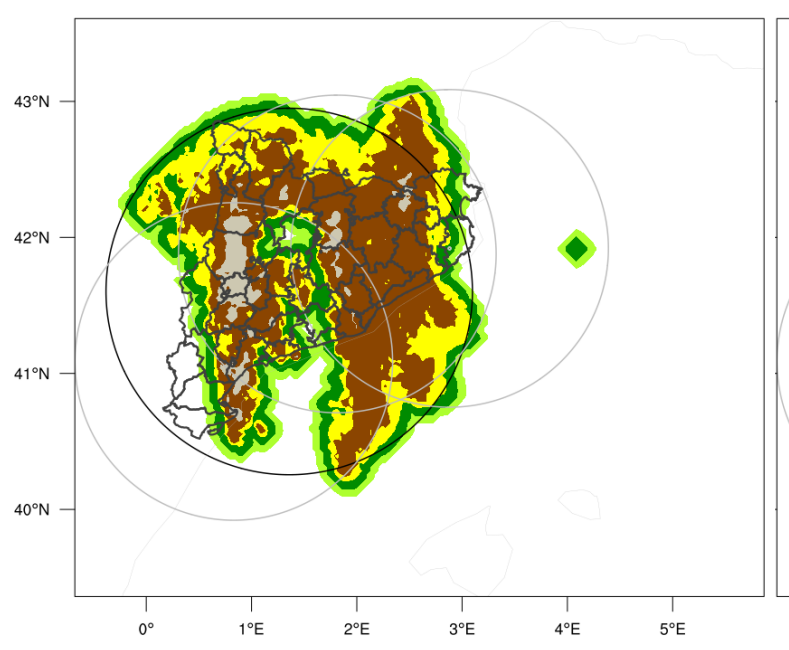

(a) Cold start (len_scaling $=0.05$ )

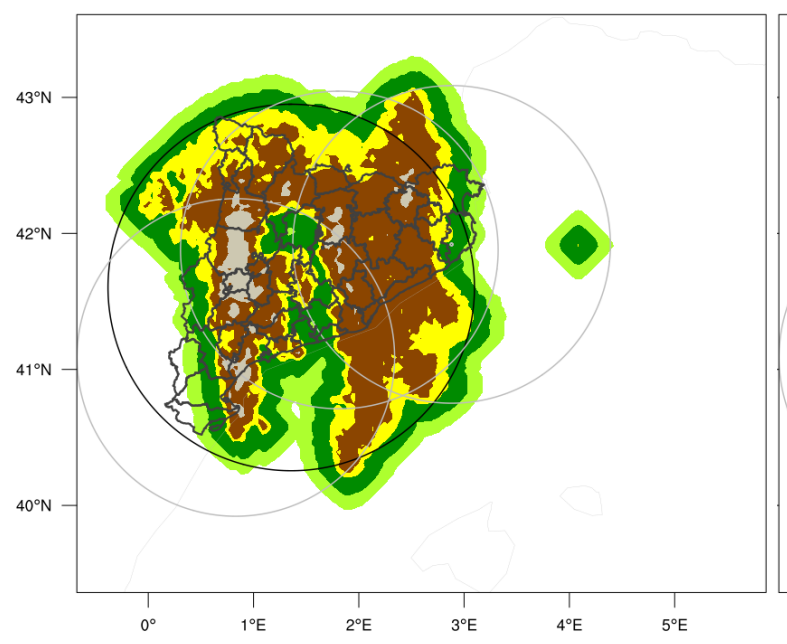

(c) Cold start (len_scaling $=0.25$ )

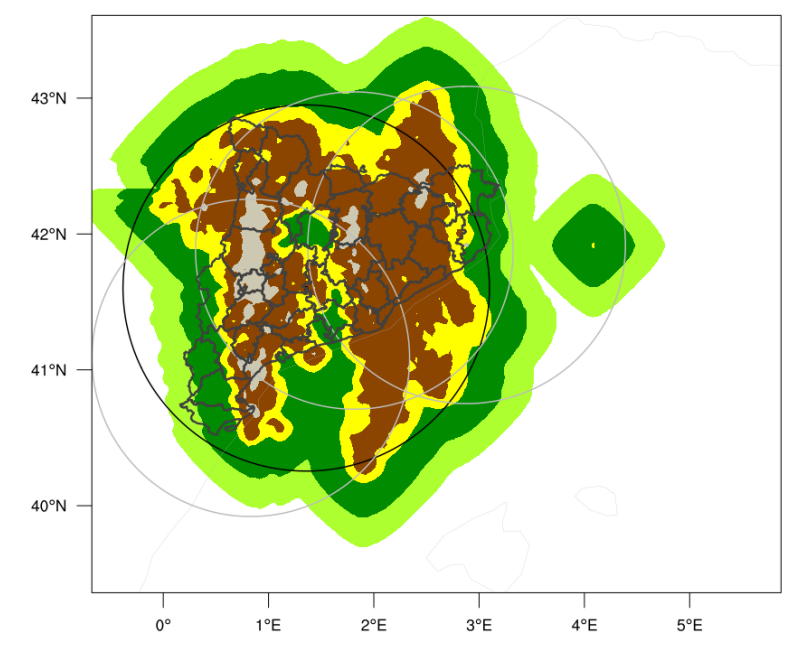

(e) Cold start (len_scaling $=0.75$ )

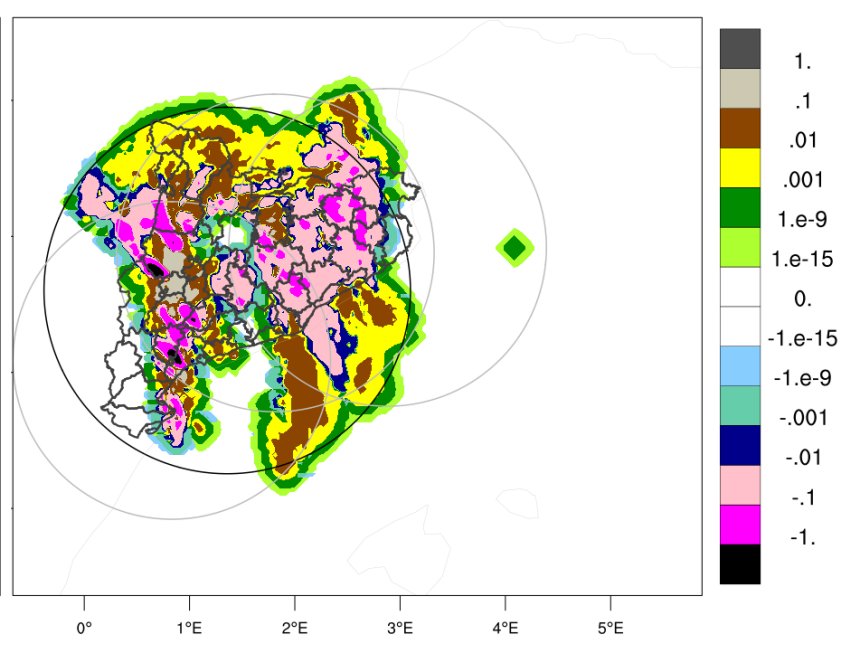

(b) Warm start (len_scaling $=0.05$ )

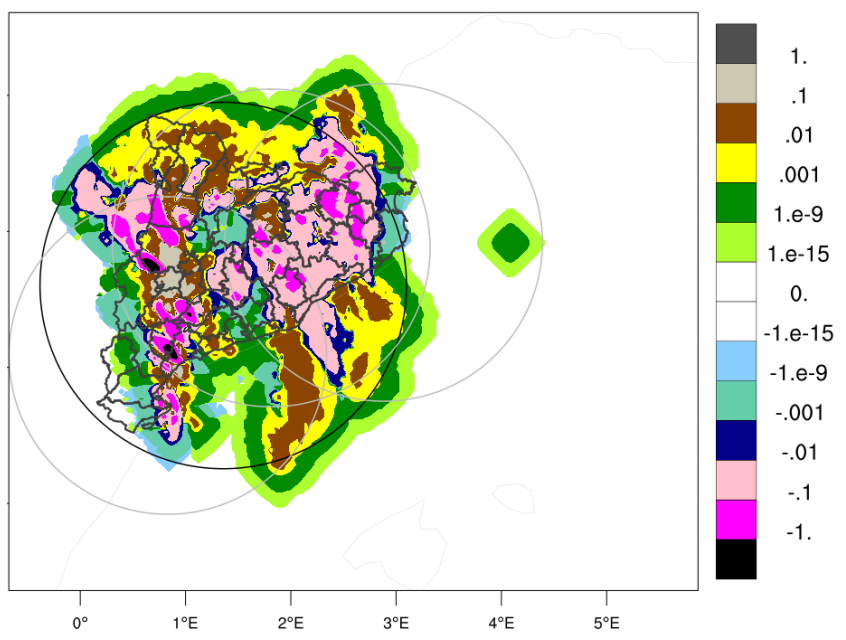

(d) Warm start (len_scaling $=0.25$ )

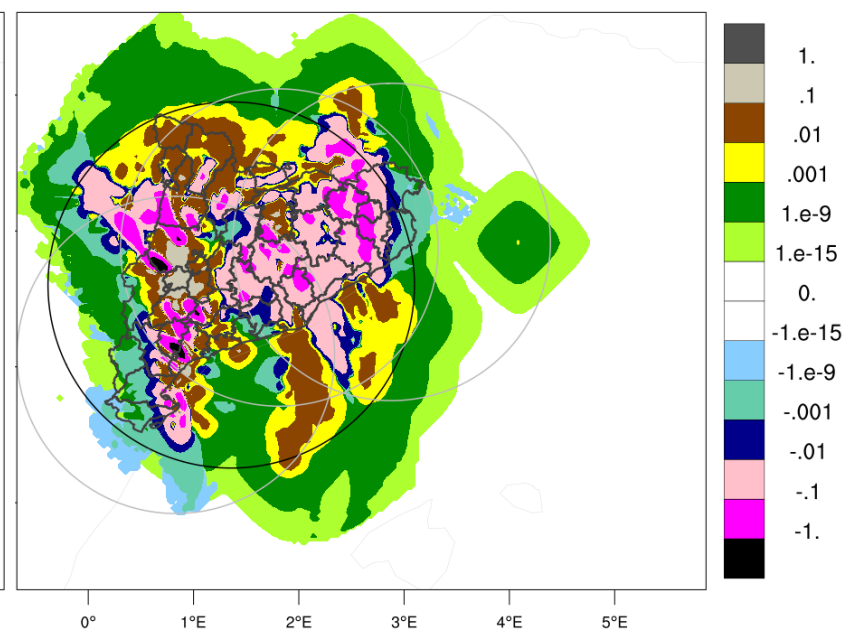

(f) Warm start (len_scaling $=0.75$ )

Figure 4: Rainwater column differences $\left(\mathrm{kg} / \mathrm{m}^{2}\right)$ between analysis and background at 15 UTC using different length scales in cold and warm starts. 
Table 1: Technical details of the radars of Catalonia in 2012

\begin{tabular}{|c|c|c|c|c|c|}
\hline \multicolumn{2}{|r|}{ Features } & PBE & CDV & LMI & PDA \\
\hline \multirow{3}{*}{ 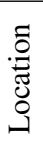 } & Latitude & 41.37 & 41.60 & 41.09 & 41.88 \\
\hline & Longitude & 1.88 & 1.40 & 0.86 & 2.99 \\
\hline & Elevation (m) & 631 & 825 & 910 & 542 \\
\hline \multirow{3}{*}{$\begin{array}{l}\bar{\varpi} \\
\stackrel{\Xi}{\Xi} \\
\bar{\rho}\end{array}$} & Maximum range $(\mathrm{km})$ & 248 & 248 & 248 & 250 \\
\hline & Antenna elevations (degrees) & 0.9 & 0.6 & 0.6 & 0.6 \\
\hline & Data & \multicolumn{4}{|c|}{ DBZ } \\
\hline \multirow{3}{*}{$\frac{\sim}{\mathfrak{\Xi}}$} & Maximum range $(\mathrm{km})$ & 128 & 148 & 128 & 128 \\
\hline & Antenna elevations (degrees) & \multicolumn{4}{|c|}{$\begin{array}{c}0.6,0.8,1,1.3,1.7,2,3 \\
\text { *PBE } 0.9,1.1,1.4,1.8,2.4,3 \\
\end{array}$} \\
\hline & Data & \multicolumn{4}{|c|}{ DBZ and VEL } \\
\hline \multirow{3}{*}{$\begin{array}{l}m \\
\stackrel{m}{\Xi} \\
\frac{\Xi}{0}\end{array}$} & Maximum range $(\mathrm{km})$ & 128 & 148 & 128 & 128 \\
\hline & Antenna elevations (degrees) & \multicolumn{4}{|c|}{$\begin{array}{c}4,5,6,8,10,13,16,21,27 \\
* \operatorname{PBE~} 4,5,6,8,10,13,16\end{array}$} \\
\hline & Data & \multicolumn{4}{|c|}{ DBZ and VEL } \\
\hline
\end{tabular}

most sensitive parameters of 3DVAR, especially the length scale. Sun et al. (2016) got better forecasts when they used length scale 0.5 and CV7. Chou and Huang (2011) and Ha and Lee (2012) performed several tests trying to find the correct length scale over the range of 0.1 to 1 in their respective experiments.

In this study, focused on the precipitation forecast, the rainwater column increment $\left(\mathrm{kg} / \mathrm{m}^{2}\right)$ after 3DVAR was analyzed in a number of experiments employing the same variance (2.5) and length scale values of $0.05,0.10$, $0.25,0.50,0.75$ and 1 in every control variable. The length scale experiments were implemented in cold and warm assimilations at $15 \mathrm{UTC}$, in order to know how this parameter affected the representation of reflectivity in terms of rainwater.

Fig. 4a, 4c and $4 \mathrm{e}$ show the inner domain and how the length scale parameter affects the rainwater increments in cold starts. The experiments at all length scales feature a field of rainwater resembling the maximum reflectivity measured by the radars at 15 UTC (Fig. 3b). The effect of a different length scale is especially visible in values below $0.001 \mathrm{~kg} / \mathrm{m}^{2}$ and single points where their propagation can be seen more clearly. Radar boundary rainwater spreads as the length scale increases. The similarity between the field of reflectivity and rainwater is especially visible in their respective maxima, even keeping a close and logical relationship between intensity and location.

In cold assimilations rainwater is not present in the background; therefore, the assimilation process will inevitably moisten the radar precipitation areas and only positive increases of rainwater are possible. The rainwater increase in cold assimilation was only possible using the Wang et al. (2013) technique; if the Xiao et al. (2005) technique had been used, the increase would have been zero.

Fig. $4 \mathrm{~b}, 4 \mathrm{~d}$ and $4 \mathrm{f}$ show how the length scale affects rainwater increments in warm starts. The length scale causes propagation very similar to cold starts but less homogeneous. This happens because in warm assimilations the background contains rainwater, then the assimilation process may increase or decrease the amount of rainwater in the analysis according to the differences between the radar data observations and the background field. It is also seen that length scales greater than 0.5 cause larger propagation in warm start than in cold start.

Combining observations from the network composed of four radars, it was possible to determine the total rainwater mixing ratio increase produced by cold and warm assimilations at 15 UTC. Understandably, the amount of rainwater varies according to cold or warm starts. In warm starts for example, rainwater reached values up to $4 \mathrm{~kg} / \mathrm{m}^{2}$ in the background (not shown), increase (up to $1 \mathrm{~kg} / \mathrm{m}^{2}$ ) and decrease (larger than $1 \mathrm{~kg} / \mathrm{m}^{2}$ ).

\subsection{Forecast experiments}

The WRF model ran in cold and warm starts, each with the six length scales mentioned above; thus we obtained twelve 5-hour precipitation forecasts at 20 UTC for each analysis performed at 15 UTC. Fig. 5 and 6 display how the 1-hour accumulated precipitation forecast changes as the length scale increases in cold and warm starts.

The precipitation forecasts were compared with the Hydrometeorological Integrated Forecasting Tool (EHIMI), elaborated by the Catalan Meteorological Service (Trapero et al., 2009), which provides hourly quantitative precipitation estimates (QPE) derived from radar data and automatic surface stations. Since the resolution of the EHIMI is 1.2 $\mathrm{km}$, it was necessary to bi-linearly interpolate the data to the same resolution of the model in domain three $(3 \mathrm{~km})$. The 


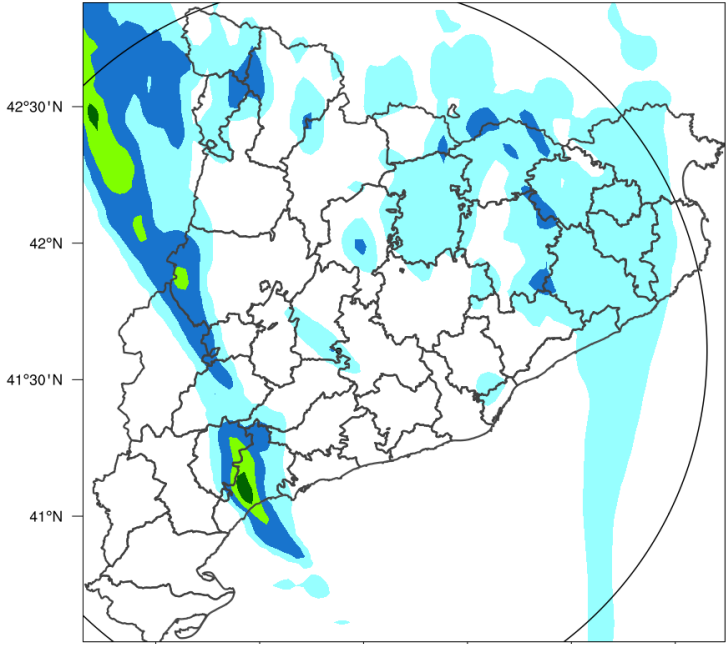

(a) WRF fcst (len_scaling $=0.05)$

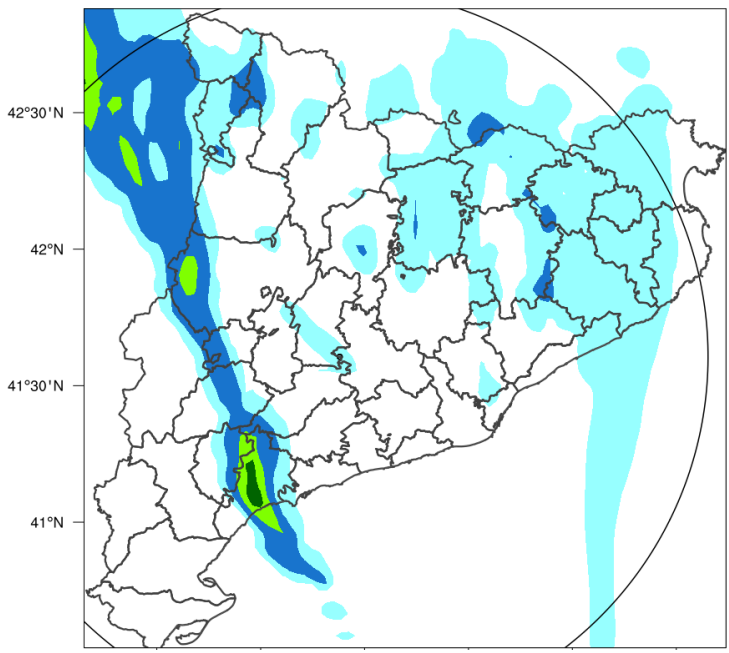

(c) WRF fcst (len_scaling $=0.25)$

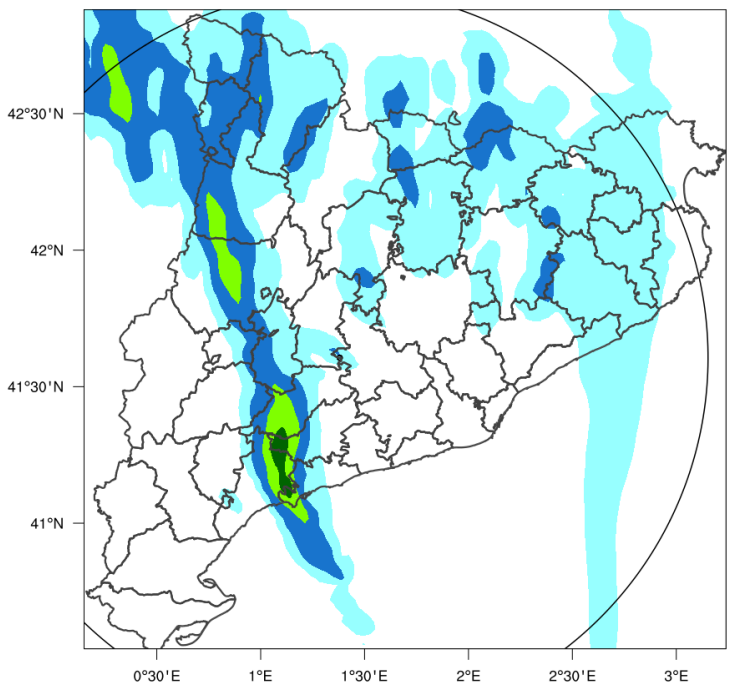

(e) WRF fcst (len_scaling $=0.75$ )

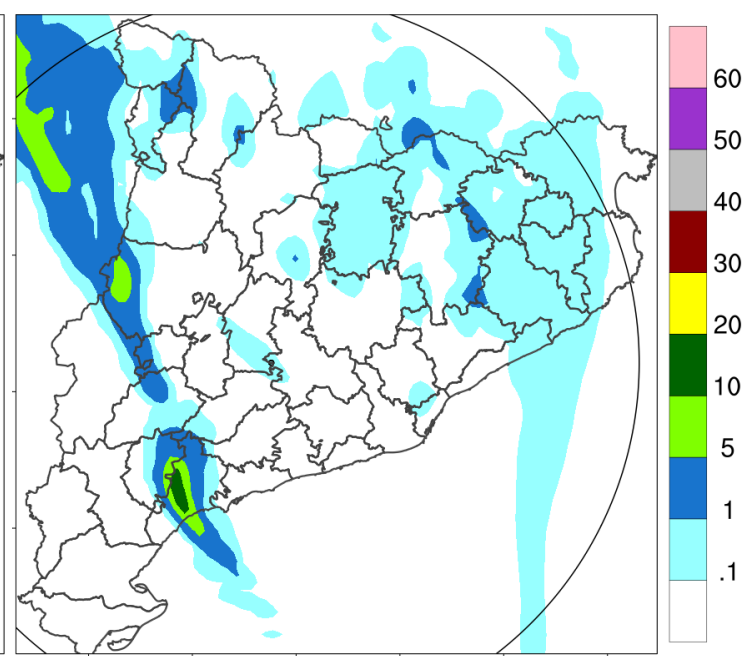

(b) WRF fcst (len_scaling $=0.10$ )

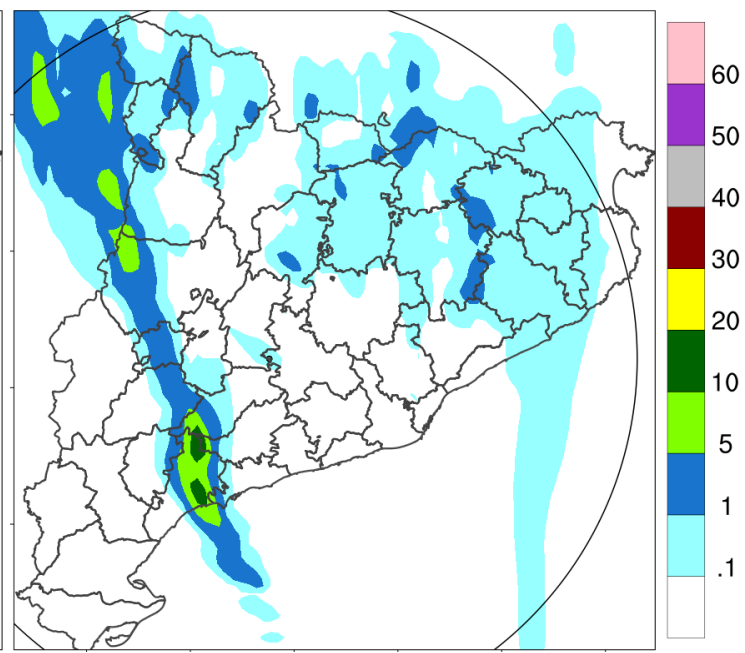

(d) WRF fcst (len_scaling $=0.50$ )

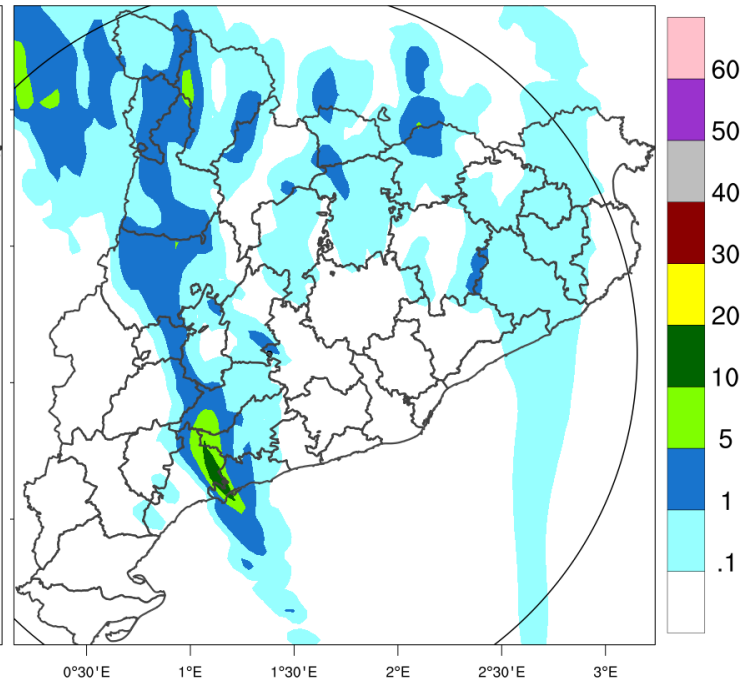

(f) WRF fcst (len_scaling = 1)

Figure 5: Hourly accumulated precipitation forecasts (mm) from 19 to 20 UTC according to length scale used in cold starts. 


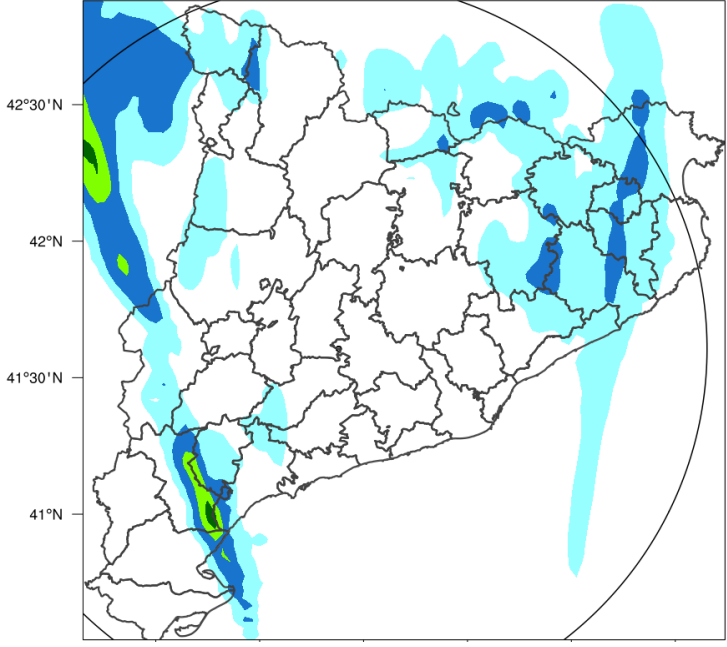

(a) WRF fcst (len_scaling $=0.05)$

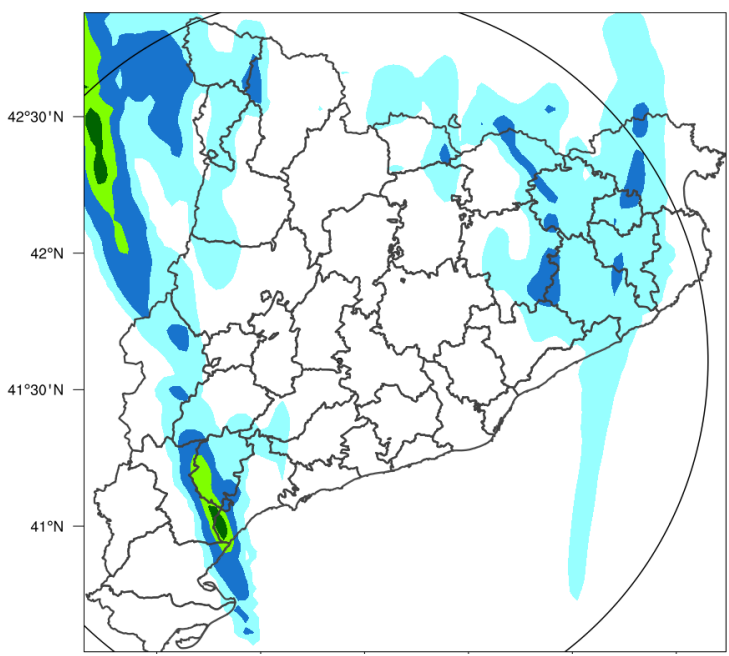

(c) WRF fcst (len_scaling $=0.25)$

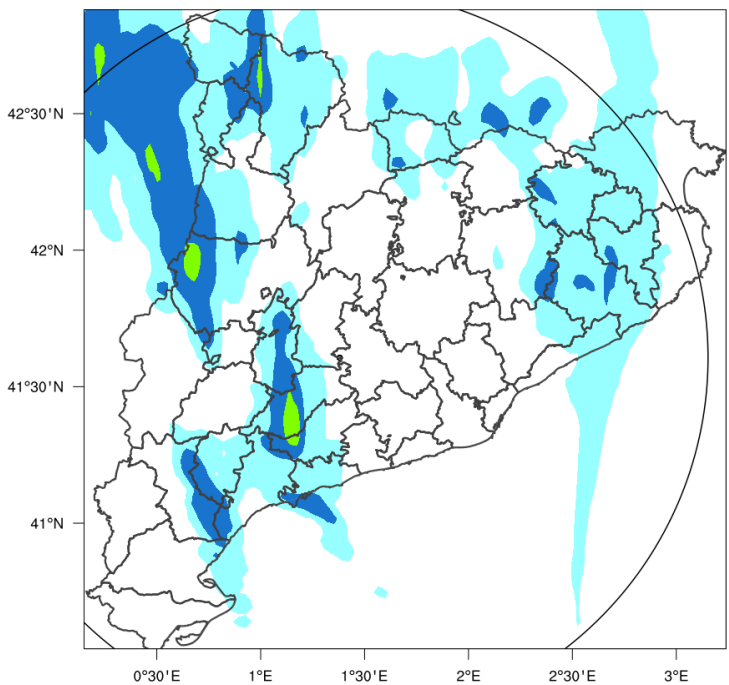

(e) WRF fcst (len_scaling $=0.75)$

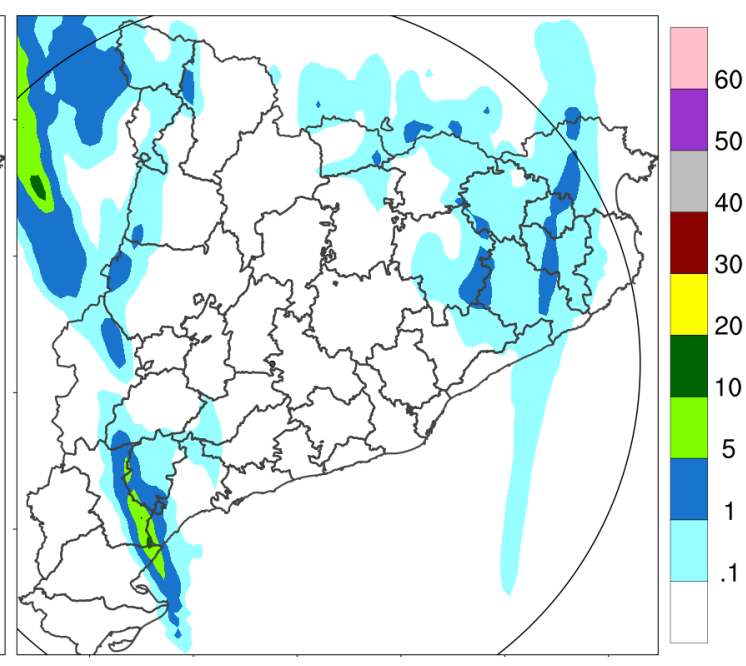

(b) WRF fcst (len_scaling $=0.10$ )

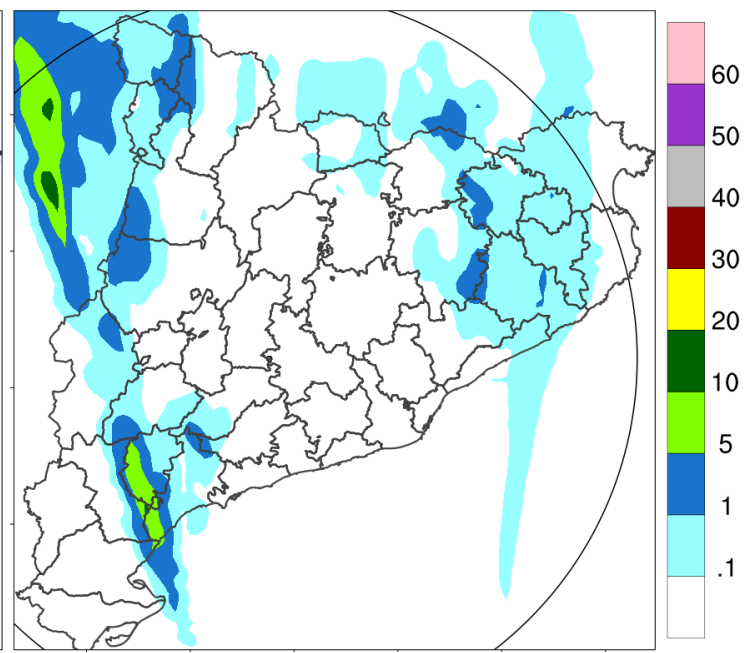

(d) WRF fcst (len_scaling $=0.50$ )

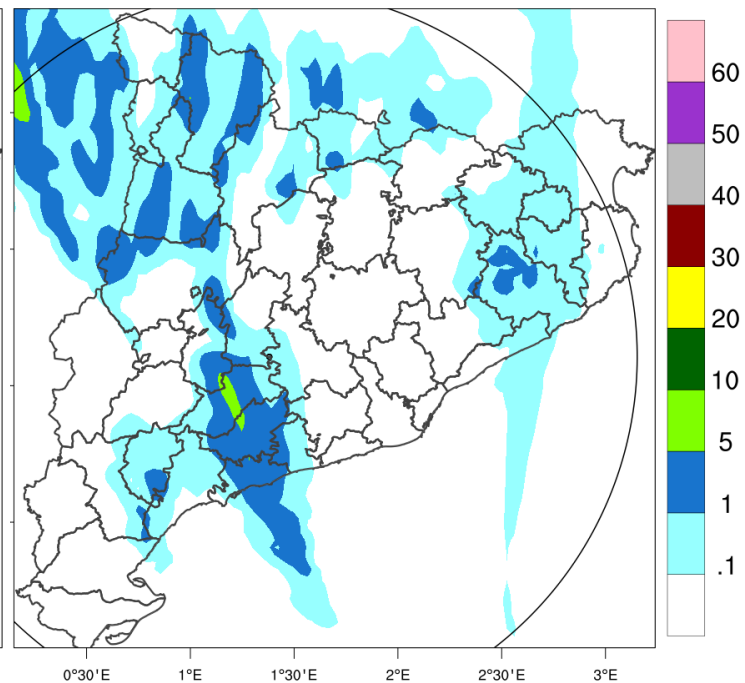

(f) WRF fcst (len_scaling = 1)

Figure 6: Hourly accumulated precipitation forecasts $(\mathrm{mm})$ from 19 to 20 UTC according to length scale used in warm starts. 


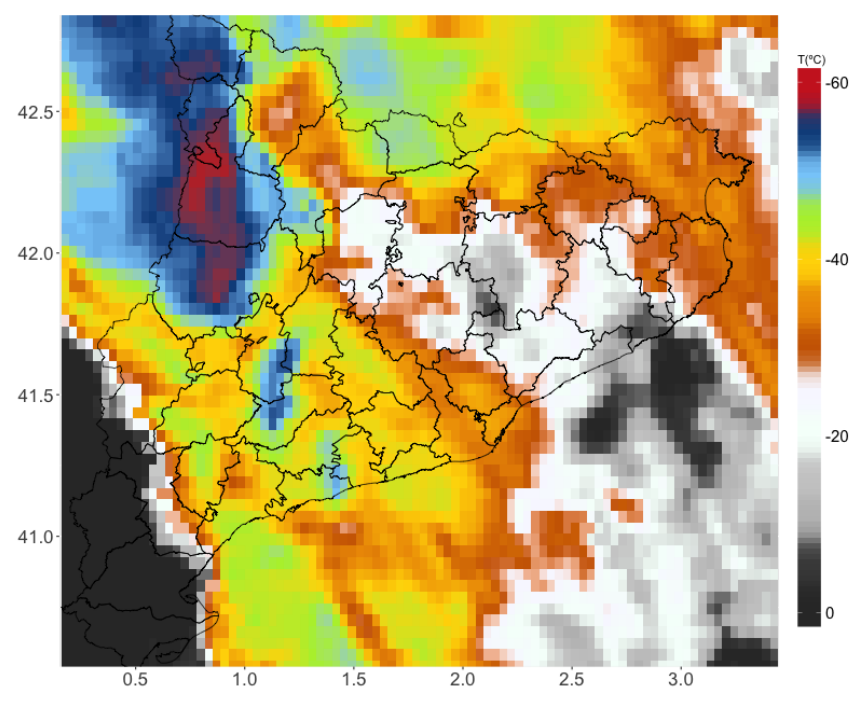

Figure 7: Cloud top temperature at 19:30 UTC 21 March 2012 derived from the Meteosat-10 $(10.8 \mu \mathrm{m}$ infrared channel).

observations clearly show that an MCS crosses Catalonia forming two maximum precipitation areas, an small one to the north and another to the south with precipitations over 40 $\mathrm{mm}$ in one hour (Fig. 1), from 19 to 20 UTC.

With the aim of evaluating whether the MCS extended to the NW as predicted by the WRF but not visible with the EHIMI product (there is a lack of observational data in this zone), the WRF forecasts were checked against the $10.8 \mu \mathrm{m}$ image from Meteosat-10 at 19:30 UTC (Fig. 7). This image showed the MCS spread far beyond the Pyrenees (N of Catalonia) and the NW convective processes seemed possible.

In cold starts, although all the length scales used in the analysis simulated the MCS, the length scale 0.75 (Fig. 5e) was qualitatively chosen as the best because the two precipitation maxima were very well located and their shape and extent corresponded to the observations. Length scales of 0.05 (Fig. 5a), 0.10 (Fig. 5b) and 1 (Fig. 5f) were discarded because precipitation forecasts between 1 and 5 $\mathrm{mm}$ were not spatially continuous throughout the system.

Warm simulations with length scales 0.75 (Fig. 6e) and 1 (Fig. 6f) yielded poor results with respect to the observed precipitation field (Fig. 1), it was not even possible to see the general structure of the MCS. Although the other length scales cause a similar precipitation forecast, we subjectively chose the results of the experiment obtained with the length scale 0.25 (Fig. 6c) as the best, because they reproduced the maximum precipitation structure in the south.

In cold and warm experiments, as the length scale is increased, the MCS shifts from SW to NE, but this trend was more noticeable in warm starts with length scales greater than 0.5 ; demonstrating that in warm starts, the WRF model is more sensitive to this parameter and should be used with caution. We infer that the SW to NE movement is due to the wide range of influence given to the observations with higher length scales and its close relationship with the wind components in that direction. According to the results obtained in this stage, we used length scale 0.75 in all cases where the WRF ran in cold start and 0.25 in warm starts.

A set of nine simulations were performed with the WRF 3DVAR system in cold and warm starts using the Wang et al. (2013) technique in the first eight and Xiao et al. (2007) in the last one (Warm ASS_15-4R-rf). The length scale of these experiments was set according to the previous paragraph.

As shown in Figure 8, the first four were WRF cold starts and the next five were warm starts. The first two experiments (Cold 12 and Cold ASS_12) were initialized at 12 UTC without and with radar data assimilation respectively, and the next seven were all initialized at 15 UTC. In the case of the third and fourth experiments (Cold 15 and Cold ASS_15), WRF ran without and with data assimilation, the fifth (Warm 15) without assimilation, the sixth (Warm ASS_15-1R) using only CDV radar data, the seventh (Warm ASS_15-4R) with assimilation and the eighth (Warm 2ASS-4R) ran by assimilating radar data at two times, at 12 and 15 UTC.

In general, all the experiments provided a reasonably good overview of the spatial extension of the precipitation field at 20 UTC (Fig. 9). The main differences between them were in the location and maximum precipitation amount. Even the nearest forecast underestimating the maximum amounts of precipitation reached between $10-20 \mathrm{~mm}$ while the EHIMI product gave $40-50 \mathrm{~mm}$ (Fig. 1).

Cold 12 (Fig. 9a) and Cold ASS_12 (Fig. 9b) cases were the worst ones as was expected after having been initialized three hours earlier. There is a lack of spatial continuity in the precipitation field associated to the elongated-shaped MCS.

There are also no significant differences between the results in the two first cases and Warm 15 case (Fig. 9e). Although the experiments were initialized with cold and warm starts (the latter three hours after the first ones) with different boundary conditions, the precipitation forecast is very similar. It seems that the precipitation field is more sensitive to changes in the first guess than to changes in boundary conditions.

By comparing the precipitation forecasts obtained from Cold 15 (Fig. 9c) and Warm 15 (Fig. 9e) without data assimilation, we obtained better results in the cold start case.

When comparing experiment Warm ASS_15-1R (Fig. 9f) with Warm ASS_15-4R (Fig. 9g), differences in precipitation location and shape were not very apparent. This could have been caused because the radar used in experiment Warm 15 was the best located for the study area and contributes with more data in the assimilation process. However, the maximum amount of precipitation was best simulated by Warm ASS_15-4R.

The Warm 2ASS-4R experiment (Fig. 9h) kept the precipitation between 1 and $5 \mathrm{~mm}$ in almost all the elongate system. The double assimilation and data from a robust radar network positively impact the total amount of simulated 


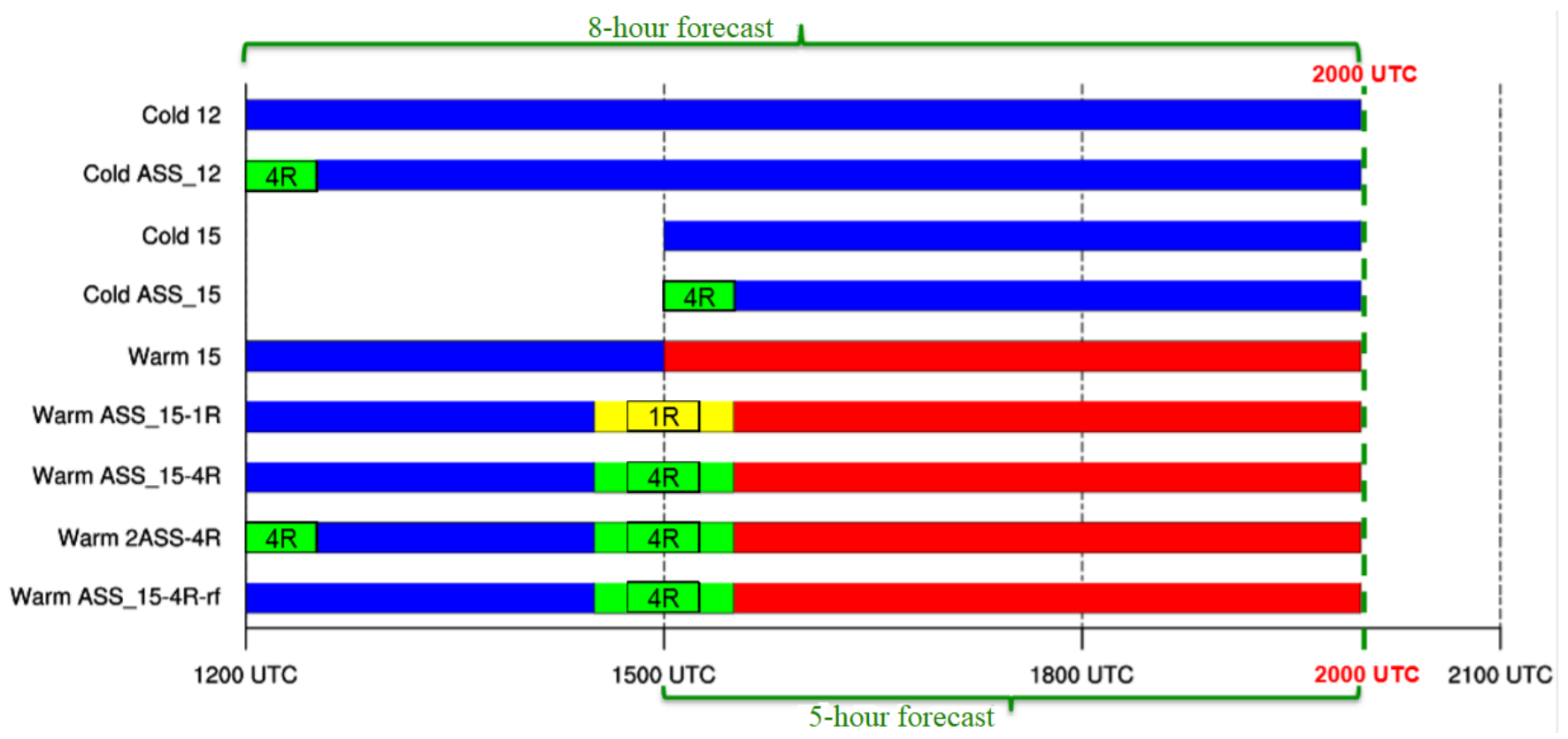

Figure 8: The characteristics of the forecast experiment. Blue represents cold start, red warm start, green represents radar data assimilation using radar network (four radars) and yellow shows radar data assimilation using only the CDV radar.

precipitation in the study area; nevertheless, it was not possible to precisely locate precipitation maxima.

The Warm ASS_15-4R-rf experiment (Fig. 9i) seemed to have a larger precipitation area of $1-5 \mathrm{~mm}$ than other experiments, but it also had the particularity of forecasting the weakest maximum precipitation in the northern part of the MCS, and although it is not visible in the EHIMI product, the infrared satellite image (Fig. 7) suggests that there was substantial convective cloudiness in that area. This situation could be explained because in the study area, it is difficult to generate precipitation under warm rain parameterizations.

The experiment that best located and quantified the maximum amount of precipitation was Cold ASS_15 (Fig. 9d), and it was also the one that best represents the elongated and compact shape of the convective system. This could occur because the background provided by the GFS model seems to be much better than the background generated by previous runs of the WRF model and because the area of Catalonia has a strong radar coverage capable of generating a realistic, accurate and full analysis of the rainwater field.

\section{Conclusion}

The study shows a high variation in the WRF precipitation nowcasting associated to the length scale parameter (it represents the radius of influence around the position of an observation) of the 3DVAR system when radar data is assimilated. In cold starts (using GFS model outputs as background), values equal or lower than 0.75 give satisfactory forecasts, even length scale 1 yields reasonable results. While in warm starts (using WRF forecasts as background), values equal or greater than 0.75 incorrectly represented the elongated shape of precipitation field associated with the MCS. Therefore, length scale does not have the same impact for forecasts initialized in cold or warm starts, it is necessary to adjust this parameter for each case.

To qualitatively compare the results obtained using radar data assimilation and cold or warn starts, or not, the following evaluation table is made:

Table 2: Qualitative comparison of forecasts

\begin{tabular}{|l|l|}
\hline Experiments & Best results \\
\hline \hline Cold 15 vs. Cold ASS_15 & Cold ASS_15 \\
\hline Warm 15 vs. Warm ASS_15-4R & Warm ASS_15-4R \\
\hline Cold 15 vs. Warm 15 & Cold 15 \\
\hline Cold ASS_15 vs. Warm ASS_15-4R & Cold ASS_15 \\
\hline
\end{tabular}

According to Table 2, the best results are obtained when using radar data assimilation and the WRF model in cold start.

In comparison with a single radar, an integrated radar network provides two advantages: data availability closer to the surface and better representation of the initial state of the atmosphere as a consequence of better coverage. In our work, these improvements are noticeable in the calculation of precipitation maxima obtained in Warm ASS_15-1R (01 radar) versus Warm ASS_15-1R (04 radars).

Of the two methods of radar data assimilation available in 3DVAR, the technique proposed by Wang et al. (2013) admits assimilation of rainwater in cold starts and shows better results in this study than the Xiao et al. (2007) technique.

Forecasts are affected by changes in their initial, 


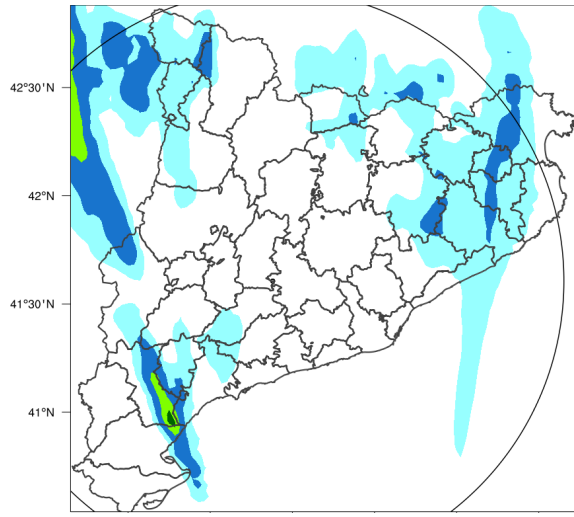

(a) Cold 12

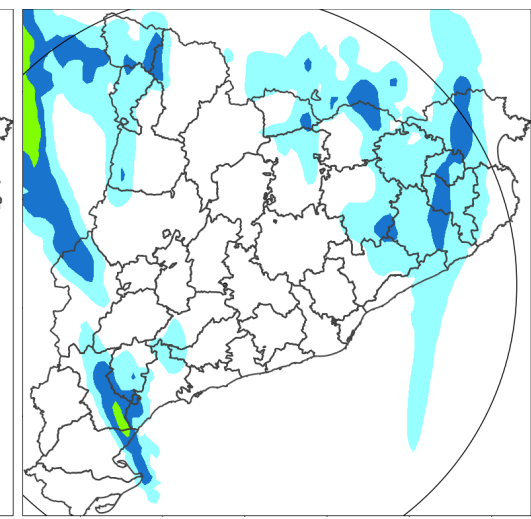

(b) Cold ASS_12

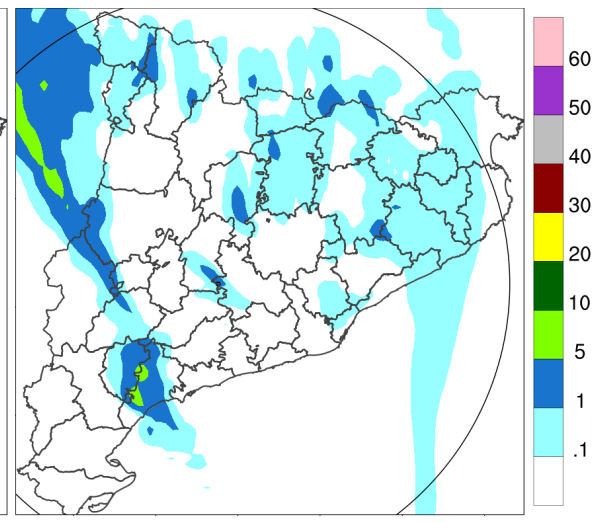

(c) Cold 15

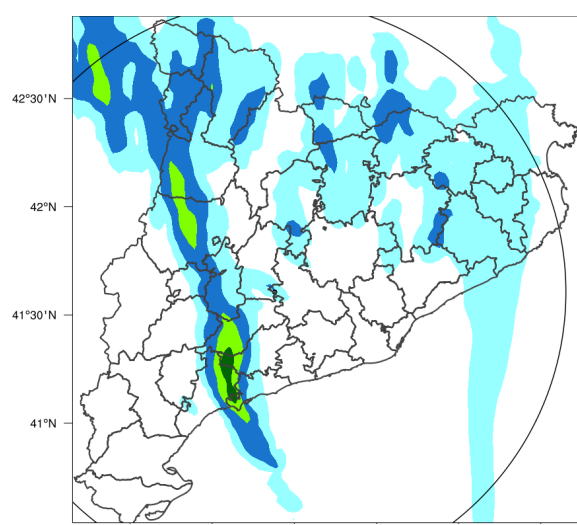

(d) Cold ASS_15

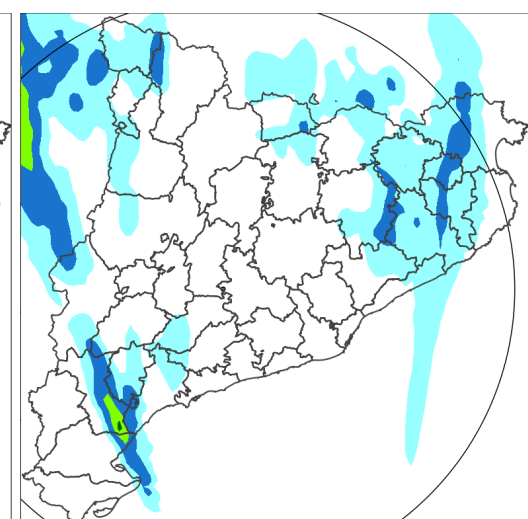

(e) Warm 15

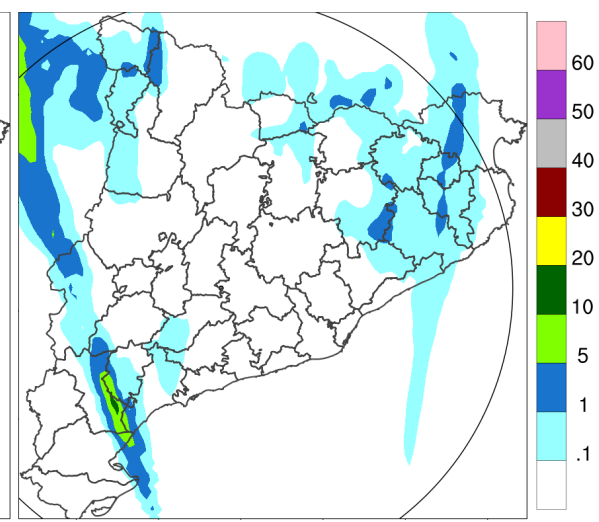

(f) Warm ASS_15-1R

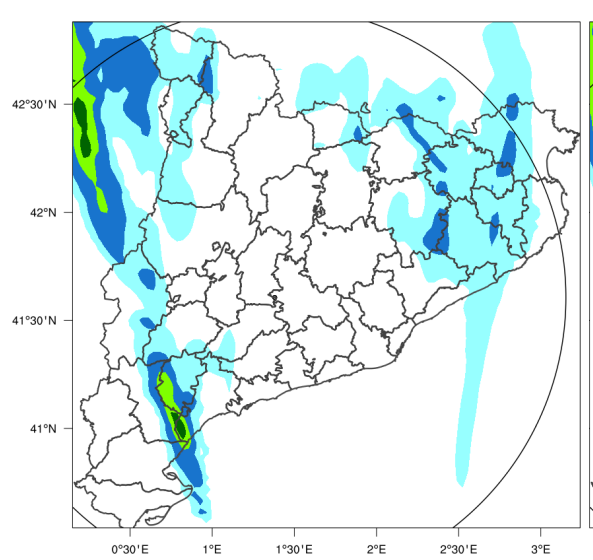

(g) Warm ASS_15-4R

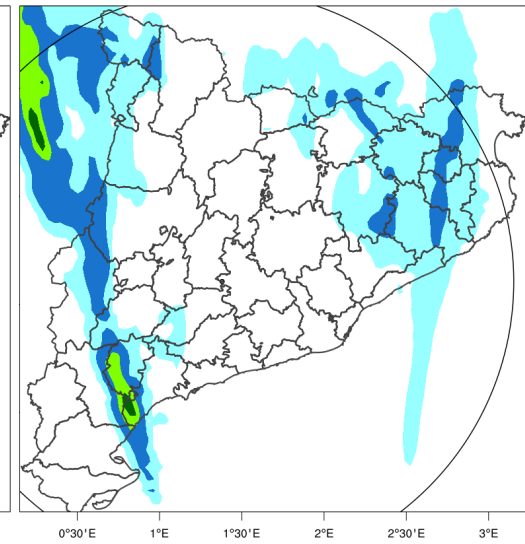

(h) Warm 2ASS-4R

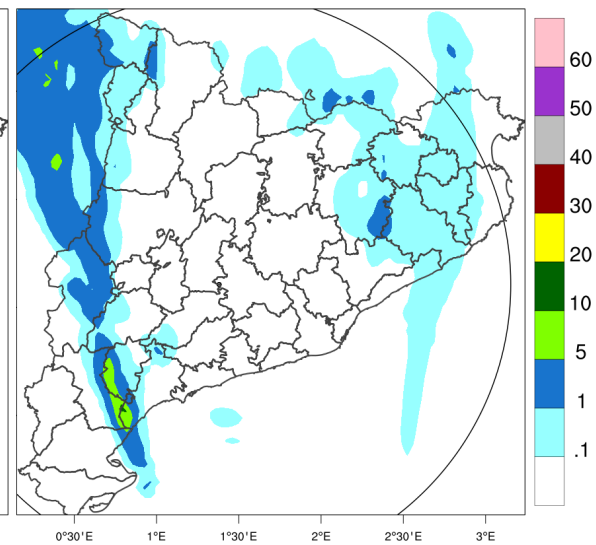

(i) Warm ASS_15-4R-rf

Figure 9: Hourly accumulated precipitation forecasts $(\mathrm{mm})$ at 20 UTC for each of the cases mentioned in Fig. 8.

lower and lateral conditions. In this study, the modification of the initial conditions causes the main differences on precipitation forecasts.

Although warm starts have the advantage of double assimilation (cold assimilation at 12 and warm assimilation at 15 UTC) and better results would be expected, in this study, however, the cold run at 15 UTC has better effects on precipitation forecast.

For this particular case, the best precipitation forecast is obtained using a cold start with length scale of 0.75 . The
WRF model is able to nicely simulate the MCS and although it failed to simulate the maximum amount of precipitation properly (10-20 instead of 40-50 $\mathrm{mm}$ and 5-10 instead of 20-30 mm measured in one hour), it located the position of the two precipitation maxima reasonably well.

Radar data assimilation positively impacted the precipitation nowcasting at 20 UTC associated with the elongated convective system that affected Catalonia on March 21, 2012. Nevertheless, it is necessary to evaluate more case studies in order to verify whether the characteristics found 
here are repetitive and thus support a quantitative analysis.

Acknowledgements. We would like to thank the National Center for Atmospheric Research for allowing a scientific internship to the first author during 2015-2016, access to the Yellowstone server and the VDRAS quality control module, as well as Dr. Juanzhen Sun in the Data Assimilation Section for her invaluable support and advice. Finally, we would like to thank the Meteorological Service of Catalonia for providing the raw radar data and also EUMETSAT for providing satellite data.

\section{References}

Arasa, R., Porras, I., Domingo-Dalmau, A., Picanyol, M., Codina, B., González, M. Á., and Piñón, J., 2016: Defining a Standard Methodology to Obtain Optimum WRF Configuration for Operational Forecast: Application over the Port of Huelva (Southern Spain), Atmospheric and Climate Sciences, 06, 329350, doi:10.4236/acs.2016.62028.

Barker, D., Huang, X.-Y., Liu, Z., Auligné, T., Zhang, X., Rugg, S., Ajjaji, R., Bourgeois, A., Bray, J., Chen, Y., Demirtas, M., Guo, Y.-R., Henderson, T., Huang, W., Lin, H.-C., Michalakes, J., Rizvi, S., and Zhang, X., 2012: The Weather Research and Forecasting Model's Community Variational/Ensemble Data Assimilation System: WRFDA, Bulletin of the American Meteorological Society, 93, 831-843, doi:10.1175/BAMS-D-11-00167.1.

Barker, D. M., Huang, W., Guo, Y.-R., Bourgeois, a. J., and Xiao, Q. N., 2004: A Three-Dimensional Variational Data Assimilation System for MM5: Implementation and Initial Results, Monthly Weather Review, 132, 897-914, doi:10.1175/1520-0493(2004) 132<0897:ATVDAS $\rangle 2.0 . C O ; 2$.

Bech, J., Arús, J., Castán, S., Pineda, N., Rigo, T., Montanyà, J., and van der Velde, O., 2015: A study of the 21 March 2012 tornadic quasi linear convective system in Catalonia, Atmospheric Research, 158-159, 192-209, doi:10.1016/j.atmosres.2014.08. 009.

Capel Molina, J. J., 2000: Los Sistemas Convectivos de Mesoescala y su influencia en la España mediterránea, PAPELES DE GEOGRAFÍA, 32, 29-43, https://dialnet.unirioja.es/servlet/ articulo? codigo $=105631$.

Chou, C.-B. and Huang, H.-P., 2011: The Impact of Assimilating Atmospheric Infrared Sounder Observation on the Forecast of Typhoon Tracks, Advances in Meteorology, 2011, 1-10, doi: 10.1155/2011/803593.

Courtier, P., Thépaut, J., and Hollingsworth, A., 1994: A strategy for operational implementation of $4 D$-Var, using an incremental approach, Quarterly Journal of the Royal Meteorological Society, 120, 1367-1387, doi:10.1002/qj.49712051912.

Dee, D. P. and da Silva, A. M., 2003: The Choice of Variable for Atmospheric Moisture Analysis, Monthly Weather Review, 131, 155-171, doi:10.1175/1520-0493(2003)131<0155:TCOVFA $\rangle 2$. $0 . \mathrm{CO} ; 2$.

Descombes, G., Auligné, T., Vandenberghe, F., Barker, D. M., and Barré, J., 2015: Generalized background error covariance matrix model (GEN_BE v2.0), Geoscientific Model Development, 8, 669-696, doi:10.5194/gmd-8-669-2015, http://www. geosci-model-dev.net/8/669/2015/.
Fujita, T. T., 1981: Tornadoes and Downbursts in the Context of Generalized Planetary Scales, Journal of the Atmospheric Sciences, 38, 1511-1534, doi:10.1175/1520-0469(1981)038<1511: TADITC $\rangle 2.0 . \mathrm{CO} ; 2$.

Ha, J.-H. and Lee, D.-K., 2012: Effect of length scale tuning of background Error in WRF-3DVAR system on assimilation of high-resolution surface data for heavy rainfall simulation, Advances in Atmospheric Sciences, 29, 1142-1158, doi:10. 1007/s00376-012-1183-Z.

Huang, X.-Y., Xiao, Q., Barker, D. M., Zhang, X., Michalakes, J., Huang, W., Henderson, T., Bray, J., Chen, Y., Ma, Z., Dudhia, J., Guo, Y., Zhang, X., Won, D.-J., Lin, H.-C., and Kuo, Y.H., 2009: Four-Dimensional Variational Data Assimilation for WRF: Formulation and Preliminary Results, Monthly Weather Review, 137, 299-314, doi:10.1175/2008MWR2577.1.

Iacono, M. J., Delamere, J. S., Mlawer, E. J., Shephard, M. W., Clough, S. A., and Collins, W. D., 2008: Radiative forcing by long-lived greenhouse gases: Calculations with the AER radiative transfer models, Journal of Geophysical Research, 113, D13 103, doi:10.1029/2008JD009944.

Ingleby, N. B., 2001: The statistical structure of forecast errors and its representation in The Met. Office Global 3-D Variational Data Assimilation Scheme, Quarterly Journal of the Royal Meteorological Society, 127, 209-231, doi:10.1002/qj. 49712757112.

Janjić, Z. I.: The Step-Mountain Eta Coordinate Model: Further Developments of the Convection, Viscous Sublayer, and Turbulence Closure Schemes, doi:10.1175/1520-0493(1994) 122〈0927:TSMECM $\rangle$ 2.0.CO;2, 1994.

Jankov, I., Gallus, W. A., Segal, M., and Koch, S. E., 2007: Influence of Initial Conditions on the WRF-ARW Model QPF Response to Physical Parameterization Changes, Weather and Forecasting, 22, 501-519, doi:10.1175/WAF998.1.

Jirak, I. L., Cotton, W. R., and McAnelly, R. L., 2003: Satellite and Radar Survey of Mesoscale Convective System Development, Monthly Weather Review, 131, 2428-2449, doi: 10.1175/1520-0493(2003)131〈2428:SARSOM $>2.0 . C O ; 2$.

Kain, J. S., 2004: The Kain-Fritsch Convective Parameterization: An Update, Journal of Applied Meteorology, 43, 170-181, doi: 10.1175/1520-0450(2004)043〈0170:TKCPAU $\rangle 2.0 . C O ; 2$.

Kain, J. S., Xue, M., Coniglio, M. C., Weiss, S. J., Kong, F., Jensen, T. L., Brown, B. G., Gao, J., Brewster, K., Thomas, K. W., Wang, Y., Schwartz, C. S., and Levit, J. J., 2010: Assessing Advances in the Assimilation of Radar Data and Other Mesoscale Observations within a Collaborative Forecasting-Research Environment, Weather and Forecasting, 25, 1510-1521, doi:10.1175/2010WAF2222405.1.

Lepoittevin, Y. and Herlin, I., 2015: Assimilation of radar reflectivity for rainfall nowcasting, in: 2015 IEEE International Geoscience and Remote Sensing Symposium (IGARSS), pp. 933-936, IEEE, doi:10.1109/IGARSS.2015.7325919.

Lim, E. and Sun, J., 2010: A Velocity Dealiasing Technique Using Rapidly Updated Analysis from a Four-Dimensional Variational Doppler Radar Data Assimilation System, Journal of Atmospheric and Oceanic Technology, 27, 1140-1152, doi: 10.1175/2010JTECHA1300.1.

Liu, J., Bray, M., and Han, D., 2013: Exploring the effect of data assimilation by WRF-3DVar for numerical rainfall prediction with different types of storm events, Hydrological Processes, 27, 3627-3640, doi:10.1002/hyp.9488. 
Mercader, J., 2010: Results of the meteorological model WRF-ARW over Catalonia, using different parameterizations of convection and cloud microphysics, Tethys, Journal of Weather and Climate of the Western Mediterranean, doi:10.3369/tethys.2010.7.07.

Mitchell, K., Ek, M., Gayno, G., Wegiel, J., and Cuenca, R. H.: Clay.

Mlawer, E. J., Taubman, S. J., Brown, P. D., Iacono, M. J., and Clough, S. A., 1997: Radiative transfer for inhomogeneous atmospheres: RRTM, a validated correlated-k model for the longwave, Journal of Geophysical Research: Atmospheres, 102, 16663-16 682, doi:10.1029/97JD00237.

Monin, A. and Obukhov, A., 1954: Basic laws of turbulent mixing in the surface layer of the atmosphere, Contrib. Geophys. Inst. Acad. Sci. USSR, 151 number, e187.

Mukul Tewari, N., Tewari, M., Chen, F., Wang, W., Dudhia, J., LeMone, M. A., Mitchell, K., Ek, M., Gayno, G., Wegiel, J., and Cuenca, R. H.: Implementation and verification of the unified NOAH land surface model in the WRF model (Formerly Paper Number 17.5), in: 20th Conference on Weather Analysis and Forecasting/16th Conference on Numerical Weather Prediction, pp. 11-15, NCAR, 2004.

NCAR: Data Assimilation (WRFDA), in: WRF - ARW V3: User's Guide, chap. 6, Boulder, Colorado, USA, http: //www2.mmm.ucar.edu/wrf/users/wrfda/Docs/user_guide_V3.9. 1/WRFDA_Users_Guide.pdf, 2017.

Parrish, D. F. and Derber, J. C.: The National Meteorological Center's Spectral Statistical-Interpolation Analysis System, doi: 10.1175/1520-0493(1992)120〈1747:TNMCSS〉2.0.CO;2, 1992.

Richardson, L. F., 1992: Weather prediction by numerical process. By Lewis F. Richardson. Cambridge (University Press), 1922. 4․ Pp. xii + 236. 30s.net, Quarterly Journal of the Royal Meteorological Society, 48, 282-284, doi:10.1002/qj. 49704820311.

Rigo, T. and Llasat, M. C., 2004: A methodology for the classification of convective structures using meteorological radar: Application to heavy rainfall events on the Mediterranean coast of the Iberian Peninsula, Natural Hazards and Earth System Science, 4, 59-68, doi:10.5194/nhess-4-59-2004.

Skamarock, W. C., 2004: Evaluating Mesoscale NWP Models Using Kinetic Energy Spectra, Monthly Weather Review, 132, 3019-3032, doi:10.1175/MWR2830.1.

Skamarock, W. C., Klemp, J. B., Dudhia, J., Gill, D. O., Barker, D. M., Duda, M. G., Huang, X.-Y., Wang, W., and Powers, J. G., 2008: A Description of the Advanced Research WRF Version 3, NCAR TECHNICAL NOTE, NCAR/TN-47, doi: 10.5065/D68S4MVH.

Sugimoto, S., Crook, N. A., Sun, J., Xiao, Q., and Barker, D. M., 2009: An Examination of WRF 3DVAR Radar Data Assimilation on Its Capability in Retrieving Unobserved Variables and Forecasting Precipitation through Observing System Simulation Experiments, Monthly Weather Review, 137, 4011-4029, doi: 10.1175/2009MWR2839.1.

Sun, J., 2005: Initialization and Numerical Forecasting of a Supercell Storm Observed during STEPS, Monthly Weather Review, 133, 793-813, doi:10.1175/MWR2887.1.

Sun, J. and Crook, N. A., 1997: Dynamical and Microphysical Retrieval from Doppler Radar Observations Using a Cloud Model and Its Adjoint. Part I: Model Development and Simulated Data Experiments, Journal of the Atmospheric Sciences, 54, 1642-1661, doi:10.1175/1520-0469(1997)054〈1642: DAMRFD $>2.0 . \mathrm{CO} ; 2$.
Sun, J. and Wang, H., 2013: Radar Data Assimilation with WRF 4D-Var. Part II: Comparison with 3D-Var for a Squall Line over the U.S. Great Plains, Monthly Weather Review, 141, 22452264, doi:10.1175/MWR-D-12-00169.1.

Sun, J., Wang, H., Tong, W., Zhang, Y., Lin, C.-Y., and Xu, D., 2016: Comparison of the Impacts of Momentum Control Variables on High-Resolution Variational Data Assimilation and Precipitation Forecasting, Monthly Weather Review, 144, 149169, doi:10.1175/MWR-D-14-00205.1.

Thompson, G., Rasmussen, R. M., and Manning, K., 2004: Explicit Forecasts of Winter Precipitation Using an Improved Bulk Microphysics Scheme. Part I: Description and Sensitivity Analysis, Monthly Weather Review, 132, 519-542, doi:10.1175/ 1520-0493(2004)132<0519:EFOWPU $\rangle 2.0 . C O ; 2$.

Thompson, G., Field, P. R., Rasmussen, R. M., and Hall, W. D., 2008: Explicit Forecasts of Winter Precipitation Using an Improved Bulk Microphysics Scheme. Part II: Implementation of a New Snow Parameterization, Monthly Weather Review, 136, 5095-5115, doi:10.1175/2008MWR2387.1.

Trapero, L., Bech, J., Rigo, T., Pineda, N., and Forcadell, D., 2009: Uncertainty of precipitation estimates in convective events by the Meteorological Service of Catalonia radar network, Atmospheric Research, 93, 408-418, doi:10.1016/j.atmosres. 2009.01.021.

Trapero, L., Bech, J., and Lorente, J., 2013: Numerical modelling of heavy precipitation events over Eastern Pyrenees: Analysis of orographic effects, Atmospheric Research, 123, 368-383, doi: 10.1016/j.atmosres.2012.09.014.

Wang, H., Sun, J., Fan, S., and Huang, X. Y., 2013: Indirect assimilation of radar reflectivity with WRF $3 D$-var and its impact on prediction of four summertime convective events, Journal of Applied Meteorology and Climatology, 52, 889-902, doi: 10.1175/JAMC-D-12-0120.1.

White, A. A.: A view of the equations of meteorological dynamics and various approximations, in: Large-Scale Atmosphere-Ocean Dynamics, edited by Norbury, J. and Roulstone, I., pp. 58,88, Cambridge University Press, Cambridge, doi: 10.1017/CBO9780511549991.003, 2000.

Woolard, E. W., 1922: L. F. Richardson on weather prediction by numerical process, Monthly Weather Review, 50, 72-74, doi: 10.1175/1520-0493(1922)50<72:LFROWP $>2.0 . C O ; 2$.

Xiao, Q. and Sun, J., 2007: Multiple-Radar Data Assimilation and Short-Range Quantitative Precipitation Forecasting of a Squall Line Observed during IHOP_2002, Monthly Weather Review, 135, 3381-3404, doi:10.1175/MWR3471.1.

Xiao, Q., Kuo, Y.-H., Sun, J., Lee, W.-C., Lim, E., Guo, Y.R., and Barker, D. M., 2005: Assimilation of Doppler Radar Observations with a Regional 3DVAR System: Impact of Doppler Velocities on Forecasts of a Heavy Rainfall Case, Journal of Applied Meteorology, 44, 768-788, doi:10.1175/JAM2248.1.

Xiao, Q., Kuo, Y.-H., Sun, J., Lee, W.-C., Barker, D. M., and Lim, E., 2007: An Approach of Radar Reflectivity Data Assimilation and Its Assessment with the Inland QPF of Typhoon Rusa (2002) at Landfall, Journal of Applied Meteorology and Climatology, 46, 14-22, doi:10.1175/JAM2439.1.

Yanagisawa, M., 2000: Momentum Transfer in Oblique Impacts: Implications for Asteroid Rotations, Icarus, 146, 270-288, doi: 10.1006/icar.2000.6389.

Yanagisawa, M., Hasegawa, S., and Shirogane, N., 1996: Momentum and Angular Momentum Transfer in Oblique 
Impacts: Implications for Asteroid Rotations, Icarus, 123, 192 206, doi:10.1006/icar.1996.0149.

Yang, Y., Uddstrom, M., and Duncan, M., 2011: Effects of short spin-up periods on soil moisture simulation and the causes over New Zealand, Journal of Geophysical Research Atmospheres, 116, doi:10.1029/2011JD016121. 